\title{
Effectiveness of different tutorial recitation teaching methods and its implications for TA training
}

\author{
Kathleen M. Koenig, ${ }^{1}$ Robert J. Endorf, ${ }^{2}$ and Gregory A. Braun ${ }^{3}$ \\ ${ }^{1}$ Department of Physics, Wright State University, Dayton, Ohio 45435, USA \\ ${ }^{2}$ Department of Physics, University of Cincinnati, Cincinnati, Ohio 45221, USA \\ ${ }^{3}$ Department of Physics, Xavier University, Cincinnati, Ohio 45207, USA
}

(Received 18 August 2006; published 15 May 2007)

\begin{abstract}
We present results from a comparative study of student understanding for students who attended recitation classes that used different teaching methods. Student volunteers from our introductory calculus-based physics course attended a special recitation class that was taught using one of four different teaching methods. A total of 272 students were divided into approximately equal groups for each method. Students in each class were taught the same topic, "Changes in Energy and Momentum," from Tutorials in Introductory Physics. The different teaching methods varied in the amount of student and teacher engagement. Student understanding was evaluated through pre- and post-tests. Our results demonstrate the importance of the instructor's role in teaching recitation classes. The most effective teaching method was for students working in cooperative learning groups with the instructors questioning the groups using Socratic dialogue. In addition, we investigated student preferences for modes of instruction through an open-ended survey. Our results provide guidance and evidence for the teaching methods that should be emphasized in training course instructors.
\end{abstract}

DOI: 10.1103/PhysRevSTPER.3.010104

PACS number(s): 01.40.-d, 01.40.gb, 01.40.J-

\section{INTRODUCTION}

Framing the study in physics education

Many of us who teach physics are faced with a similar problem: students can mathematically solve single-step physics problems but many cannot answer simple related conceptual questions and have difficulty solving multi-step problems. ${ }^{1,2}$ Because it appears that a good understanding of the concepts is necessary for more advanced problem solving, this issue can be addressed through those alternative methods of instruction that have been shown to develop student conceptual understanding. ${ }^{3}$ Some of these methods of instruction include cooperative learning, inquiry-based instructional materials, tutoring centers, use of computers in the laboratory to model difficult physics concepts, and more interaction between the lecture instructor and students. Evidence suggests that these alternative modes of instruction are more effective at educating students. ${ }^{4-7}$ However, because many of these innovations are being implemented in the laboratory and recitation parts of physics courses, it is the graduate teaching assistants (TAs) who take on this new duty. This raises the question of whether or not TAs have enough physics background knowledge and general teaching skills to effectively use alternative modes of instruction.

The Tutorials in Introductory Physics ${ }^{8}$ is one example of an alternative method of instruction. These inquiry-based materials are typically implemented in the recitation sections of physics courses and incorporate a set of conceptual activities designed to actively engage students in the learning process of physics. As the students work in groups under the guidance of their peers and the instructor (typically a TA), misconceptions are addressed, enabling the development of a strong conceptual physics knowledge base. At various points in the Tutorial activities, the students have their reasoning checked by the TA. During these checkpoints, the TA uses directed questioning to determine the extent of student understanding of the material. If misconceptions arise, the TA guides the students to correct reasoning through additional directed questioning. This questioning process, frequently termed Socratic dialogue, is a major step in the development of students' critical thinking skills.

Alternative instruction, such as the tutorials used in this study, frequently requires more TA training than traditional teaching. Several departments have designed and implemented special training programs for their TAs and descriptions of the programs can be found in the literature..$^{9-12}$ Unfortunately, TA training is limited by factors including (1) the lack of time TAs can devote to extensive training due to their own courses and research, (2) lack of resources and/or staff to extensively train TAs, and (3) the lack of desire of some TAs to learn better methods of teaching. Although many TA training programs have dealt with these constraints and met with success, there is no one-size-fits-all method of training due to the conditions at different universities, as well as the type of innovative instruction being used. ${ }^{13}$ In our study we have endeavored to determine what is needed to most effectively teach recitations using the Tutorials so that we can in turn determine the type and amount of training our TAs need to be as effective as possible in their teaching assignments.

\section{Implementing the Tutorials in the General Physics courses at the University of Cincinnati}

General Physics at the University of Cincinnati is a threequarter calculus-based physics course for first-year engineering students. The lecture portion of the course typically contains about 450 students enrolled in four different lecture sections taught by different physics faculty. Each lecture section (of between 100 and 125 students) meets three times weekly. In addition, the course includes small weekly recitation sections of between 20 and 25 students. Each is taught by a graduate teaching assistant and an undergraduate peer instructor. Several years ago we decided to modify this course because it had become a barrier for beginning engi- 
neering students, who had difficulty understanding basic physics concepts and were unable to solve multistep problems using these concepts. Because previous studies have shown that student understanding of concepts is improved by using instructional methods that incorporate active engagement instruction ${ }^{4}$ and research-based inquiry activities, ${ }^{1}$ we aimed to improve student performance by implementing the Tutorials in Introductory Physics in the recitation sections of the course. The Tutorials were chosen because they are a proven set of inquiry-based instructional materials that help students develop important conceptual understanding and reasoning skills. ${ }^{1}$

One of the difficulties we encountered with implementing the Tutorials, however, was that the TAs required more training than when teaching traditional recitation. The authors of the Tutorials have created an extensive training program at the University of Washington for this purpose. In their program the TAs meet weekly to work through the activities to be taught that week and to discuss common misconceptions associated with each topic. Emphasis is placed on the teaching process, and first-time TAs are paired with more experienced TAs (typically postdoctoral and graduate students in physics education), whenever possible, so that Socratic dialogue and effective teaching can be modeled. The TAs need this type of training to understand the inquiry structure of the material and to learn to lead the students by asking appropriate Socratic questions.

At the University of Cincinnati, we designed our TA training program based on elements of the program at the University of Washington, but limitations reduced the amount of training possible. Although weekly meetings enabled the TAs to work through the activities to be taught that week, a lack of time allowed for only very brief discussions of pedagogical content issues and misconceptions. Checkpoints and the use of Socratic dialogue were modeled during the weekly meetings but a lack of resources inhibited the pairing of firsttime with more experienced TAs.

As part of our initial implementation of the Tutorials, several faculty members visited the recitation classes and evaluated the TAs' performance according to the number of interactions they had with the student groups and how well they used Socratic dialogue during the checkpoints. Through these classroom visits we found that many recitation instructors performed satisfactorily, but some instructors interacted only minimally with the students, merely giving the students the correct answers at the checkpoints. These instructors needed frequent reminders to engage the students in Socratic dialogue. We have previously shown that student conceptual understanding may be affected by the TAs' ability to implement the Tutorials. ${ }^{14}$ However, in that study it was difficult to unravel the many factors that may have affected student understanding in a multiple-section course where students had different lecture and recitation instructors.

In this paper we describe a second investigation which uses a controlled comparison of student conceptual understanding of a topic after the students have been taught with different methods in a recitation class. In particular, we investigate how student understanding may be affected by the manner in which the Tutorials are taught and compare the effectiveness of the Tutorials with that of a traditional problem-solving lecture-style recitation. It is valuable to study which factors are crucial in effectively implementing the Tutorials because instructors who have not attended a University of Washington Tutorials workshop may attempt to implement the Tutorials in different manners, such as using them without Socratic dialogue or as individual worksheets. Also, limits on availability of TAs or time for training sessions may prevent some schools from implementing the $T u$ torials in an ideal fashion. This is especially difficult at schools without a large number of faculty and graduate students involved in physics education research. The question is then how significant a proper implementation is to the success of the Tutorials. The study will also address the concerns of some of our non physics education research (PER) faculty colleagues, who have doubts that the Tutorials are actually more effective than traditional recitations.

\section{OBJECTIVES AND METHODS}

The purpose of our study was to evaluate which teaching methods would be the most effective for recitation classes associated with lectures in introductory physics courses. The evaluation was based on student conceptual understanding, which was measured by pre- and post-tests given before and after recitation classes that were taught with different instructional methods. In addition, a student attitude survey was administered to investigate student preferences for the different modes of instruction implemented as part of the study.

\section{Evaluating student conceptual understanding}

We decided that the best way to evaluate student understanding with different styles of instruction was to teach the study recitation outside of the course because it would be unfair to impose an inferior method of instruction on some students. The study was performed during the seventh week of the first quarter of General Physics in the Winter quarter of 2005. The study was arranged as part of an optional, extra-credit opportunity, and all students from the four lecture sections of the course (which were taught by different physics faculty) were invited to participate. Students were informed that they could volunteer to participate in a research study that would evaluate various styles of recitation classes. Their participation in the study required them to attend one recitation class that was not part of the course. As volunteers they received extra-credit points based only on their participation. Students who did not volunteer for the research study were offered the opportunity to receive the same amount of extra credit by doing an extra online homework assignment. Of the 390 students who completed the course, a total of 272 students completed the study. The students in the study were representative of those in the course with the majority being freshmen and male, and over $90 \%$ were between the ages of 18 and 20 years. These students were assigned to one of the four styles of recitation classes. Although the assignments could not be random due to student schedules, we made every effort to create equally distributed groups. For example, we held eight sessions (two for each of the four styles) and included various days of the 
week and times of the day with some sessions held in parallel or on the same day and time the following week. The four styles of instruction were scheduled in time slots such that we would get a mixture of students from the four lecture sections of the course, and none of the study sessions overlapped the regularly scheduled lecture. When students registered for the study they indicated which sessions they were available. Most students were available for four or more of the study sessions and all were randomly assigned to one of the sessions for which they indicated their availability.

The four styles of recitation classes were (1) a traditional lecture taught by one of our physics faculty, (2) students working individually through a tutorial, (3) students working in cooperative learning groups of three or four through a tutorial, and (4) students working in cooperative learning groups through a tutorial with instructors performing checkpoints using Socratic dialogue. Style 1 was the only method that did not use a tutorial as written in the textbook. In this case the material in the tutorial exercise was rewritten as a lecture containing related problems with numerical answers. The instructor then presented the problems and the solutions at the blackboard and stated the conceptual results that the students should conclude from the example problems. The concepts presented were the same as those emphasized in the Tutorials but because the lecturer provided both the exercises and answers the students were potentially passive learners. This style was similar to traditional recitations in which textbook problems are solved by an instructor. In style 2 the students worked on the tutorial activity alone. At the checkpoints the instructors gave the students an answer key for them to check their work. The answer key was merely a slip of paper with the answers typed out for each question the students would have completed up to that particular checkpoint. This allowed the students the opportunity to correct their own written work before moving on in the tutorial exercise. This style was to evaluate how well the students would perform using inquiry-based activities without the benefit of working within a cooperative learning group and without the aid of instructor dialogue. For style 3 the students performed the tutorial activity within cooperative learning groups, and as in style 2, the instructors provided only answer keys at the checkpoints without any dialogue. This method was included to evaluate how well students would learn in cooperative groups without the benefit of instructor dialogue. Style 4 used our normal method of teaching the Tutorials with cooperative learning groups and instructors using Socratic dialogue at each checkpoint. The class was taught by an experienced TA and an undergraduate student, both of whom were proficient in using Socratic dialogue. Two sessions were held for each of the four styles of recitation classes with each participant in the study attending one session.

The tutorial activity "Changes in Energy and Momentum" was chosen for our study because it covers topics that students have difficulty understanding, and because it was not scheduled as part of the regular course. This tutorial helps students develop a better understanding of how to apply the work-energy theorem and the impulse-momentum theorem to determine the final kinetic energy and momentum of objects. Another advantage of the tutorial was that we could

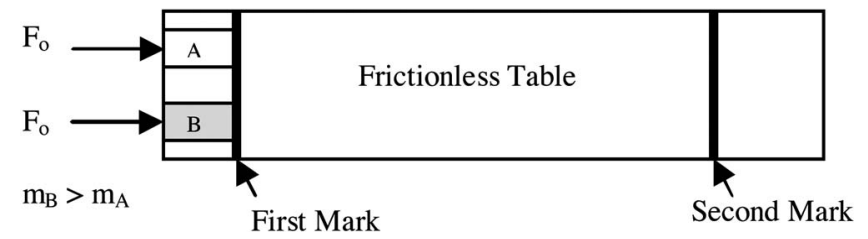

FIG. 1. Diagram (top view) used in all recitations for the pretest.

compare our results with the published pre- and post-test results from the Physics Education Group at the University of Washington. ${ }^{15}$

The pretest used for our study was the same pretest used by the University of Washington and it is provided in the Instructor's Guide for the Tutorials. ${ }^{15,16}$ The pretest shows two carts of different mass initially at rest on a frictionless horizontal table. The carts are pushed by equal constant forces between the starting mark and a second mark on the table (see Fig. 1). After passing the second mark, the force on each cart is taken away and the carts glide freely. The students are asked if the less massive cart's kinetic energy and momentum are greater than, less than, or equal to the kinetic energy and momentum of the more massive cart after both carts pass the second mark. The students are also asked to explain their answers.

The post-test contained two questions which were the same as those presented by the Physics Education Group at the University of Washington. ${ }^{15}$ The first post-test question uses the same physical setup as the pretest, but now the two carts are pushed from rest on a frictionless horizontal table by equal forces for equal time intervals instead of equal distances. The students are asked if the less massive cart's kinetic energy and momentum are greater than, less than, or equal to the kinetic energy and momentum of the more massive cart at the end of this time interval and to provide explanations for their answers. The second post-test question shows two carts of unequal mass, $A$ and $B$, on frictionless parallel tracks (see Fig. 2). Both start from rest and are pushed by equal constant forces until they cross the finish line. The more massive cart $A$ starts behind cart $B$ and the force acting on cart $B$ does not begin until cart $A$ passes it.

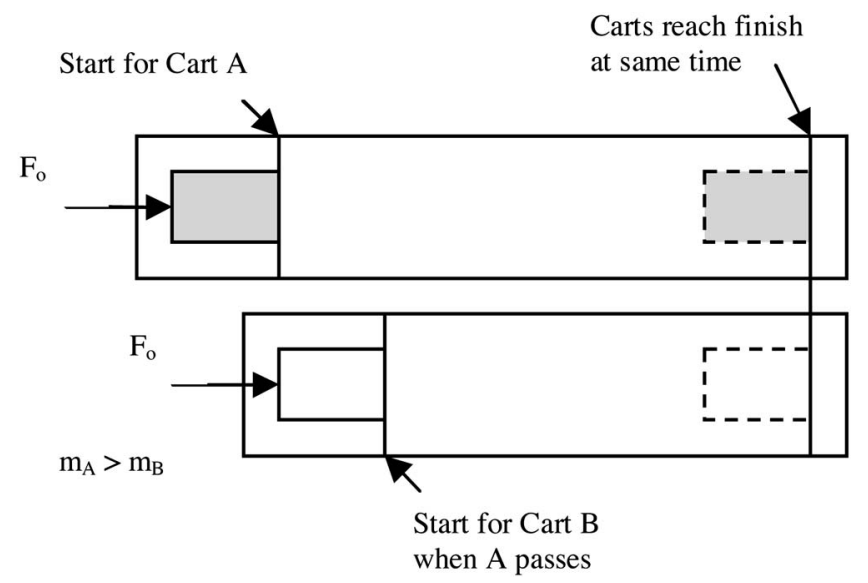

FIG. 2. Diagram (top view) used in all recitations for the second post-test question. 
TABLE I. Attitude survey questions.

Q1. What did you like about the instruction you received today as part of this study?

Q2. What did you not like about the instruction you received today as part of this study?

Q3. Compare today's experience to your regular recitation class. Which do you feel is better at teaching you physics concepts? Explain.

Q4. Compare today's experience to your regular recitation class. Which do you feel is better at teaching you how to solve physics problems? Explain.

Q5. Compare today's experience to your regular recitation class. Which do you enjoy more? Explain.

Q6. For recitation classes in the future, would you prefer today's mode of instruction over the current recitation instruction in your course? Explain.

Both carts cross the finish line at the same time with cart $B$ traveling faster than cart $A$. The students are asked if the final momentum and the final kinetic energy of cart $A$ are greater than, less than, or equal to the momentum and final kinetic energy of cart $B$. The students are also asked to provide explanations for their answers.

\section{Investigating student preferences}

As part of this study we also investigated student preferences for instruction because we were concerned about student perceptions of the course. In the past we observed complaints about the recitation portion of the course both verbally and on course evaluations. In particular, students commented that the use of the Tutorials in recitation was not related to the problem solving that they were required to do in the lecture portion of the course. They also perceived poor teaching performance of their TAs and claimed that certain TAs confused rather than clarified the topics. Some students commented that working in groups during recitation slowed them down and that they would learn just as much by completing the Tutorials at home. After observing multiple recitation classes, we found that some of the complaints were justified and could be linked to TA preparedness. Some complaints were not justified and may be attributed in part to student resistance to a nontraditional teaching style or to a general dislike of physics. We became concerned that these student frustrations may be preventing the students from fully benefiting from their recitation experience.

We investigated student preferences of modes of instruction through a six-question survey given immediately following participation in the study activities (see Table I). The questions on the survey were written by the authors to investigate (1) the aspects of recitation that are liked or disliked by the students, (2) student beliefs about the role of recitation in helping them learn physics concepts and how to solve problems, and (3) student preferences of the various modes of recitation presented during the study.
TABLE II. Student performance on the pretest questions.

\begin{tabular}{lcc}
\hline \hline & $\begin{array}{c}\text { Correct kinetic } \\
\text { energy } \\
\text { comparison of } \\
\text { Recitation style } A \text { and } B\end{array}$ & $\begin{array}{c}\text { Correct } \\
\text { momentum } \\
\text { comparison of } \\
\text { carts } A \text { and } B\end{array}$ \\
\hline Style 1 $(N=75)$ & $25 \%$ & $1 \%$ \\
Style 2 $(N=76)$ & $29 \%$ & $3 \%$ \\
Style 3 $(N=58)$ & $21 \%$ & $0 \%$ \\
Style 4 $(N=63)$ & $22 \%$ & $0 \%$ \\
\hline \hline
\end{tabular}

\section{RESULTS AND CONCLUSIONS}

\section{Comparison of pretests and post-tests}

The percentages of correct responses for the kinetic energy and momentum comparison of carts $A$ and $B$ are listed in Table II for each style of recitation. Only students with both a correct answer and correct explanation are listed. The work-energy theorem had been previously presented in lecture but the impulse-momentum theorem had not.

A correct explanation for the comparison of the kinetic energy consisted of using the work-energy theorem $(F \Delta x$ $=\Delta K)$ to show equal kinetic energy changes $(\Delta K)$ for both carts. The correct explanation for the momentum comparison consisted of stating that cart $B$ had a greater momentum by applying the impulse-momentum theorem $(F \Delta t=\Delta p)$. Although rare, several students demonstrated correct understanding by solving for the kinetic energies and momentums using kinematics equations.

The pretest results for each style are similar with percentage of correct kinetic energy comparisons of carts $A$ and $B$ ranging from $21 \%$ to $29 \%$ and with percentage of correct momentum comparisons of the carts ranging from $0 \%$ to $3 \%$. The results of $t$-test comparisons of the ratios of correct answers for each style indicate that statistically $(p>0.05)$ the students in each style had a similar initial understanding of the topics. As a second check for group similarity, the scores were obtained for the identical block exams of each student and the average exam scores for each style group were also found to be similar (ranging from $57 \%$ to $61 \%$, with ratio $t$ tests indicating no statistically significant difference between groups, $p>0.05$ ). The low percentage of students with correct answers for the momentum comparison of the carts may be because the impulse-momentum theorem had not yet been covered in lecture class. Our pretest results, compared to the results obtained by the Physics Education Group at the University of Washington (15\% and $5 \%$, respectively), ${ }^{15}$ are slightly higher for the kinetic energy comparison of the carts and about the same for the momentum comparison.

Our percentages of correct responses for the two post-test questions are shown in Tables III and IV. The percentage of correct responses for the kinetic energy and the momentum comparisons of the carts for both questions were about twice as large for students in style 4 than those of the other three styles of recitations. The higher percentages for style 4 in all four responses are statistically significant $(p<0.01)$ based on ratio $t$-test comparisons with styles 1,2 , and 3 . The percent- 
TABLE III. Student performance on post-test question 1.

\begin{tabular}{lcc}
\hline \hline & $\begin{array}{c}\text { Correct kinetic } \\
\text { energy } \\
\text { comparison of } \\
\text { carts } A \text { and } B\end{array}$ & $\begin{array}{c}\text { Correct } \\
\text { momentum } \\
\text { comparison of } \\
\text { carts } A \text { and } B\end{array}$ \\
\hline Style 1 $(N=75)$ & $16 \%$ & $20 \%$ \\
Style 2 $(N=76)$ & $12 \%$ & $11 \%$ \\
Style 3 $(N=58)$ & $12 \%$ & $21 \%$ \\
Style 4 $(N=63)$ & $35 \%$ & $43 \%$ \\
\hline \hline
\end{tabular}

age of correct responses for styles 1, 2, and 3 are all statistically comparable based on ratio $t$-test comparisons, except for the results of style 3 on post-test question 2 which are low compared to the other styles.

The low percentage of correct answers on the post-test questions for styles 1,2 , and 3 indicate that few of these students gained an understanding of how to correctly apply the work-energy and the impulse-momentum theorems in a new context. The higher percentage of correct answers for the kinetic energy comparison of carts $A$ and $B$ for post-test question 2 compared to post-test question 1 may be because the work-energy theorem is easier to apply in post-test question 2. Our percentages of correct responses on the post-test for style 4 , based on a $t$-test comparison of the ratios of correct answers, are statistically consistent with the results obtained at the University of Washington ${ }^{15}$ (35\% and 50\%, respectively, for post-test question $1 ; 30 \%$ and $45 \%$, respectively, for post-test question 2) except that our percentage of correct answers for the kinetic energy question on post-test 2 is higher. It should be noted that there are some significant differences between our study and that of the University of Washington which may account for the differences in results here. The results at the University of Washington were obtained from a wide range of tutorial sections taught under real-world conditions including nonideal TAs and noncontrolled tutorial sections.

Our results indicate that, even with what appears to be the most effective instruction in the study (style 4), only $35-64 \%$ of the students were able to correctly answer the post-test questions. We did not have the students complete the homework pages associated with this tutorial, and having done so may have increased the number of students with correct answers. However, as noted by researchers at the University of Washington, the concepts associated with this tutorial are very difficult and additional research is probably needed.

TABLE IV. Student performance on post-test question 2.

\begin{tabular}{lcc}
\hline \hline Recitation style & $\begin{array}{c}\text { Correct kinetic } \\
\text { energy } \\
\text { comparison }\end{array}$ & $\begin{array}{c}\text { Correct } \\
\text { momentum } \\
\text { comparison }\end{array}$ \\
\hline Style 1 $(N=75)$ & $35 \%$ & $19 \%$ \\
Style 2 $(N=76)$ & $26 \%$ & $16 \%$ \\
Style 3 $(N=58)$ & $12 \%$ & $12 \%$ \\
Style 4 $(N=63)$ & $64 \%$ & $38 \%$ \\
\hline \hline
\end{tabular}

TABLE V. Students who continued to use same incorrect reasoning on pre- and post-test question 1.

\begin{tabular}{lcc}
\hline \hline Recitation style & $\begin{array}{c}\text { Kinetic energy } \\
\text { comparison of } \\
\text { carts } A \text { and } B\end{array}$ & $\begin{array}{c}\text { Momentum } \\
\text { comparison of } \\
\text { carts } A \text { and } B\end{array}$ \\
\hline Style 1 $(N=75)$ & $52 \%$ & $72 \%$ \\
Style 2 $(N=76)$ & $65 \%$ & $84 \%$ \\
Style 3 $(N=58)$ & $71 \%$ & $76 \%$ \\
Style 4 $(N=63)$ & $19 \%$ & $33 \%$ \\
\hline \hline
\end{tabular}

\section{Use of incorrect logic before and after instruction}

The data presented in the previous section include only the percentage of students with both correct answers and correct explanations on the pre- and post-tests. It is also useful to look at the percentage of students who continued to use the same incorrect logic even after instruction (see Tables V and VI). A beginning step in overcoming deeply held misconceptions involves moving students away from their initial incorrect ideas.

These data indicate that style 4 was better at moving students away from their initial incorrect reasoning as demonstrated on the pretest. However, it is not apparent from these values whether the students moved closer to a correct model or just resorted to another incorrect model. The purpose of the Tutorial activity chosen for this study was to introduce students to the work-kinetic energy and impulse-momentum theorems. On the pretest, no student referred to these theorems unless they actually got the question and explanation correct (see Tables III and IV). On the post-test there were quite a few students who tried to apply the theorems to the questions but got incorrect results in their attempts (see Tables VII and VIII).

For the kinetic energy comparison for both questions, styles 1,2 , and 3 were statistically comparable based on ratio $t$-test comparisons. Style 4 had a significantly higher percentage than styles 2 and $3(p<0.05)$ for post-test question 1 and significantly higher percentage $(p<0.05)$ than all styles for post-test question 2 . For the momentum comparison for posttest question 1 , styles 1,2 , and 3 were statistically comparable and style 4 had a significantly higher percentage ( $p$ $<0.05)$ than all styles based on ratio $t$-test comparisons. However, for the momentum comparison for post-test question 2, the percentages are so small that with our statistics we

TABLE VI. Students who continued to use same incorrect reasoning on pre- and post-test question 2 .

\begin{tabular}{lcc}
\hline \hline Recitation style & $\begin{array}{c}\text { Kinetic energy } \\
\text { comparison of } \\
\text { carts } A \text { and } B\end{array}$ & $\begin{array}{c}\text { Momentum } \\
\text { comparison of } \\
\text { carts } A \text { and } B\end{array}$ \\
\hline Style 1 $(N=75)$ & $55 \%$ & $68 \%$ \\
Style 2 $(N=76)$ & $59 \%$ & $76 \%$ \\
Style 3 $(N=58)$ & $72 \%$ & $85 \%$ \\
Style 4 $(N=63)$ & $24 \%$ & $33 \%$ \\
\hline \hline
\end{tabular}


TABLE VII. Students who acknowledged but incorrectly applied the theorems on post-test question 1. Note that no students acknowledged these theorems on the pretest without applying them correctly.

\begin{tabular}{lcc}
\hline \hline & $\begin{array}{c}\text { Kinetic energy } \\
\text { comparison of } \\
\text { carts } A \text { and } B\end{array}$ & $\begin{array}{c}\text { Momentum } \\
\text { comparison of } \\
\text { carts } A \text { and } B\end{array}$ \\
\hline Style 1 $(N=75)$ & $24 \%$ & $7 \%$ \\
Style 2 $(N=76)$ & $18 \%$ & $4 \%$ \\
Style 3 $(N=58)$ & $12 \%$ & $4 \%$ \\
Style 4 $(N=63)$ & $40 \%$ & $24 \%$ \\
\hline \hline
\end{tabular}

cannot state that there is a statistically significant difference in the results for the four styles. Our results in general, in addition to those shown in Tables V and VI, suggest that style 4 was not only better at moving students away from their prior misconceptions, but also at moving the students toward the use of the work-kinetic energy and impulsemomentum theorems even if they were not successful in achieving a final correct answer to the question.

\section{Student attitudes toward the four styles of instruction}

As part of this study we investigated various aspects of student attitude toward the style of instruction they received by administering a six-question survey immediately following their participation in the study activities (see Table I). The first two questions on the survey asked the students what they specifically liked or disliked about the style of instruction they received during the study. The remaining four questions asked how the study recitation session compared to the students' usual weekly recitation which was part of their General Physics course. (Note that the regular course recitation involved the use of the Tutorials with cooperative groups and Socratic dialogue with a TA.)

The results of question 6 , the overall preference question, are shown in Table IX. Note that the students' preferences do not agree with the effectiveness of the method as shown by the post-test results in Tables III and IV. For example, style 1 (the traditional teacher-centered recitation) was the preferred instructional method of the students, but it was clearly less effective than style 4 according to the percentage of students

TABLE VIII. Students who acknowledged but incorrectly applied the theorems on post-test question 2. Note that no students acknowledged these theorems on the pretest without applying them correctly.

\begin{tabular}{lcc}
\hline \hline & $\begin{array}{c}\text { Kinetic energy } \\
\text { comparison of } \\
\text { carts } A \text { and } B\end{array}$ & $\begin{array}{c}\text { Momentum } \\
\text { comparison of } \\
\text { carts } A \text { and } B\end{array}$ \\
\hline Style 1 $(N=75)$ & $12 \%$ & $3 \%$ \\
Style 2 $(N=76)$ & $6 \%$ & $5 \%$ \\
Style 3 $(N=58)$ & $3 \%$ & $2 \%$ \\
Style 4 $(N=63)$ & $29 \%$ & $8 \%$ \\
\hline \hline
\end{tabular}

TABLE IX. Teaching style preference question 6.

\begin{tabular}{lccc}
\hline \hline & $\begin{array}{c}\text { Preferred } \\
\text { style in study } \\
\text { over regular } \\
\text { recitation }\end{array}$ & Neutral & $\begin{array}{c}\text { Preferred } \\
\text { regular } \\
\text { course } \\
\text { recitation }\end{array}$ \\
\hline Style 1 & 51 & 24 & 25 \\
Style 2 & 15 & 12 & 73 \\
Style 3 & 30 & 30 & 40 \\
Style 4 & 43 & 55 & 2 \\
\hline \hline
\end{tabular}

who correctly answered the posttest questions.

For those students in style 1,59\% responded that they thought this was a better mode of instruction over their regular course recitation at teaching them physics concepts. In addition, $89 \%$ thought that style 1 was better at teaching them how to solve problems. Although some students cited style 1 as boring and stated that they would prefer to work in groups during recitation, 51\% (see Table IX) responded that they preferred this type of traditional recitation because it appeared more useful in preparing them for the lecture portion of the course (i.e., the assigned homework and exams). In addition, only $25 \%$ of the students indicated that they preferred their regular course recitation over style 1 and the remaining $24 \%$ were neutral with no preference between style 1 and their regular course recitation.

Style 2, which involved independent work with the Tutorials with no TA interaction, was clearly the least favorite of all the styles of instruction involved in this study. Many of the students (64\%) complained about the lack of group interaction and 36\% commented that they missed the guidance of a TA. A few students indicated that they learned about the same as they did in regular recitation but that working in groups was at least less objectionable. As indicated in Table IX, only $15 \%$ of students preferred this style of recitation which involved independent work. The majority of students (73\%) indicated that they preferred their regular course recitation and $12 \%$ were neutral.

Student responses to style 3 were somewhat mixed. In style 3 the students worked in cooperative groups but at checkpoints they were given slips of paper with written answers (no explanations) in lieu of dialogue with a TA. About $30 \%$ of the students felt neutral about style 3 (see Table IX). To our dismay, many of these students commented that this style of recitation was the same as their regular recitation, in spite of the fact that their regular recitation should have included a trained TA who engaged them in Socratic dialogue at checkpoints. In addition, another $30 \%$ of the students preferred style 3 over their regular recitation. These students indicated that the answers written out on the slips of paper given to them at checkpoints were much clearer than what they received in their regular course recitation. They commented that many times their regular TA confused them through discussions at checkpoints and that they would leave recitation not sure of what the correct answers were. The remaining $40 \%$ of students in style 3 preferred their regular course recitation. They commented that the slips of paper given during the study contained only written answers but no 
explanations. They did not like the fact that they could not ask the TA for further clarification. As indicated by the student survey responses for style 3 , it becomes evident that the role of the TA is influential on student satisfaction of instruction and possibly student understanding. This finding emphasizes the importance of training TAs on how to implement the Tutorials as well as basic teaching skills, and then monitoring their actual teaching performance in the classroom.

We designed style 4 to be what we perceived to be the ideal implementation of the Tutorials. The students worked in cooperative groups and checkpoints included Socratic dialogue with highly experienced TAs trained on the use and pedagogy of the Tutorials. We were pleased that $55 \%$ of the students (see Table IX) responded that style 4 was very similar or identical to their weekly recitation. There were very few total responses $(2 \%)$ that indicated preference for their regular weekly recitation. The remaining $43 \%$ of students in style 4 preferred the study recitation over their regular course recitation. Most indicated that the TAs used in the study were better than their regular recitation TAs. Students indicated that they did not like the poor English-speaking skills of their regular TAs nor their TAs' inability to provide clear answers during checkpoints. It should be noted that the TAs used in the study were not only highly experienced, but their English was much clearer than that of our typical graduate student TAs, and they also taught with more enthusiasm and interest. Once again we are provided with evidence that supports the importance of training and then monitoring TAs on not just the implementation of the Tutorials but on general teaching skills.

\section{DISCUSSION}

The primary purpose of this study was to investigate the level of implementation of the Tutorials that is necessary for maximum student conceptual understanding. At the University of Washington there is an extensive TA training program to enable their TAs to be better equipped to implement the Tutorials in an "ideal" fashion (i.e., students work in cooperative learning groups with TAs trained in the pedagogy of teaching specific Tutorial topics and who use Socratic dialogue to check student understanding and lead students to correct logic). After four years of implementing the Tutorials at our institution, we feel that it is valuable to study which factors are crucial in effectively implementing these materials. Our concern resides primarily in the time and resources it takes to train our TAs and the fact that, even after training, some of our TAs do not implement the Tutorials in an "ideal" fashion. We also realize that there are institutions with instructors who may not have attended a University of Washington Tutorials workshop, and they may attempt to implement the Tutorials in different manners, such as using them as individual worksheets or without Socratic dialogue.

Although it may be tempting to use the Tutorial worksheets as individual home activities to save class time or to assign the worksheets to students absent from recitation, the results of our study clearly indicate that this level of implementation of the Tutorials is no more effective than the traditional recitation that was also part of the study (i.e., stu- dents of styles 1 and 2 had similar poor post-test results).

In addition, institutions with a small number of faculty, graduate students, or funding may forgo properly training their Tutorial instructors particularly on the use of Socratic dialogue. In our experience we have found that our recitation instructors (TAs) need weekly training to prepare them for recitations that use the Tutorials. In particular, the TAs need time to work through the Tutorial worksheets beforehand, and they need guidance on how to use Socratic dialogue with each new Tutorial topic. Even with our moderate training program we have observed TAs implementing the Tutorials with very little interaction with the students. In some cases we have observed TAs who merely read through the student answers and made corrections directly on the student worksheets without any sort of dialogue with the students. Although the students may benefit from having correct answers on their worksheets, we were concerned that the lack of Socratic dialogue may reduce the level of student understanding. This was investigated through styles 3 and 4, which both used cooperative learning groups, but only style 4 incorporated the use of Socratic dialogue in checking student answers. The percentage of students in style 3 with correct answers on the post-test were significantly lower than those of style 4, which indicates the importance of Socratic dialogue in the implementation of the Tutorials. We observed during the study that students in style 3 tended to accept without question the correct answers given by the TA during checkpoints, even when the students' own original answers were incorrect. In most cases the students merely altered their answers on their worksheets without discussing the correct answers among themselves. In contrast, we observed during the study that those students in style 4 engaged in more dialogue with the TA and also among themselves when they learned that their original answers were incorrect. The Socratic dialogue initiated by the TA not only got the students to question their own understanding of the material but also seemed to generate more discussion among the students and TA. Therefore, our results show strong support for the use of Socratic dialogue when implementing the Tutorials and this emphasizes the importance of training and requiring recitation instructors to use this type of dialogue in their teaching.

Although students of style 4 in this study performed significantly better on the post-test than students of the other styles, even this group's somewhat low post-test results were disheartening (35-64\% had correct answers depending on the question), although as noted earlier they were consistent with what other researchers have found. However, we have evidence to suggest that style 4 was better than the other styles at moving students away from their initial misconceptions. In this case, a much higher percentage of students referred to the work-kinetic energy and impulse-momentum theorems in their responses on the post-test, although these students did not end up with the final correct answer. This provides evidence that the Tutorials should be used in conjunction with lecture followup and homework assignments, and that recitation classes should not be used as an isolated part of the course. It should be noted that each Tutorial activity has an accompanying homework assignment. However, due to the design of this study, we did not assign this 
additional instruction to the students so we cannot comment on its effectiveness.

A secondary purpose of this study was to provide support for the Tutorials over traditional recitation. Some of our nonPER faculty have expressed concern that the use of the Tutorials may not be as effective as the traditional recitation we have used in the past. Comparison of styles 1 and 4 clearly indicates that a nontraditional recitation can significantly impact student conceptual understanding of physics. In style 1 the students received teacher-centered instruction much like that of traditional recitation. It should be noted that this instruction was carefully developed for this study and was likely better than that typically administered in the regular recitation of the course. In style 4 the students received student-centered instruction that incorporated the use of cooperative learning groups, conceptual worksheets (Tutorials), and Socratic dialogue with the instructor. Post-test results indicate the significance of this type of nontraditional instruction at improving student conceptual understanding. This is an important finding because the Tutorials require more staff and resources to implement than traditional recitation and our results help justify the additional costs associated with their use.

Finally, results from student surveys allowed us to more fully investigate various aspects of recitation related to student preferences and beliefs. We find the results of the surveys important as we try to increase not only student conceptual understanding but also as we try to improve student satisfaction with our introductory physics courses. In particular, three themes emerged from the surveys. First, we were pleased to learn that, when the Tutorials were used, students in general preferred working in groups under the guidance of a TA. This was an important finding because we hope to continue to use the Tutorials in our recitation classes. However, the second theme that emerged was that students felt strongly that the conceptual nature of the Tutorial worksheets did not properly prepare them for the assigned homework and course exams. This is somewhat surprising to us, because one-fourth of each regular course exam and a portion of each homework assignment are directly related to work completed in the Tutorials during recitation. In addition, we know from the results of research that conceptual understanding of physics concepts has in some cases been found to improve students' ability to solve problems ${ }^{17,18}$ although this connection is apparently not evident to the students. Again, we see a discrepancy between student perceptions and actual learning. The third theme that emerged from the surveys was that student satisfaction with recitation is clearly linked to the teaching performance of the TA. TAs with poor teaching skills, including inadequate use of Socratic dialogue and/or poor oral skills, tended to frustrate their students and cause them to dislike their recitation classes.

The themes that emerged from the surveys have caused us to look more closely at how recitation is integrated into the overall course structure. It has become evident to us that we need to educate the students on the philosophy behind the Tutorials and how they can improve student problem-solving skills. Students need to feel that the concepts they are learning in recitation are important for their overall understanding of physics and that these topics are not isolated from lecture. In addition, we have come to understand that our training program for the TAs is in need of further improvement. We have a very diverse group of TAs, and although many communicate well with our students, we need to be more observant of the oral skills of all TAs before they are selected to teach recitation. We also need to spend more time monitoring TAs while they are actually teaching in the classroom, since it is evident that even with intense training it is not guaranteed that TAs will perform as we expect.

\section{FUTURE WORK}

Although it was not surprising to us that style 1 (traditional recitation) and style 2 (independent work with the Tutorials) did not yield a high percentage of students with correct post-test answers, we were surprised that style 3 had similarly low post-test results as well. We expected the cooperative learning part of style 3 to yield higher student conceptual understanding over styles 1 and 2 . In addition, the only difference between styles 3 and 4 was the interaction with the TA, and yet students of style 4 performed significantly better on the post-test than students in style 3 . In order to better discern why these particular results occurred, a future study that looks more closely at the behavior of students in styles 3 and 4 is necessary.

In addition, because the students in this study were enrolled in one of four lecture sections (different instructors) and we could not control what was taught during lecture, we administered the post-tests immediately after the recitation study sessions rather than several weeks later. Therefore, we were unable to investigate the longitudinal effects of the different styles on student conceptual understanding. An important question remains as to whether or not students of style 4 would continue to significantly outscore students of the other styles on a post-test given weeks after the study recitation was completed. In addition, because the post-test was given immediately after the recitation sessions, we did not assign the students the homework from the Tutorial text. Therefore, the effectiveness of this piece of additional instruction was not investigated in this study.

\section{ACKNOWLEDGMENTS}

We wish to thank the Physics Education Group at the University of Washington, and in particular Lillian McDermott, Peter Shaffer, and Paula Heron, for their valuable advice and support. Partial support for this work has been provided by the National Science Foundation under Grant No. DUE-0126919. 
${ }^{1}$ L. C. McDermott, "Oersted Medal Lecture 2001: Physics education research - the key to student learning," Am. J. Phys. 69, 1126 (2001).

${ }^{2}$ L. C. McDermott and E. F. Redish, "Resource letter: PER1:physics education research," Am. J. Phys. 67, 755 (1999).

${ }^{3}$ E. F. Redish and R. N. Steinberg, "Teaching physics: Figuring out what works," Phys. Today 52 (1), 24 (1999).

${ }^{4}$ R. R. Hake, "Interactive-engagement vs. traditional methods: A six-thousand-student survey of mechanics test data for introductory physics courses," Am. J. Phys. 66, 64 (1998).

${ }^{5}$ R. R. Hake, "Socratic pedagogy in the introductory physics laboratory," Phys. Teach. 30, 546 (1992).

${ }^{6}$ E. Mazur, Peer Instruction: A User's Manual (Prentice-Hall, Upper Saddle River, NJ, 1996).

${ }^{7}$ E. F. Redish, J. M. Saul, and R. N. Steinberg, "On the effectiveness of active-engagement microcomputer-based laboratories," Am. J. Phys. 65, 45 (1998).

${ }^{8}$ L. C. McDermott and P. S. Shaffer, Tutorials in Introductory Physics (Prentice Hall, Upper Saddle River, NJ, 2002).

${ }^{9}$ J. P. Birk and M. J. Kurtz, "Using cooperative learning techniques to train new teaching assistants," J. Chem. Educ. 73, 615 (1996).

${ }^{10}$ E. Etkina, "Helping graduate assistants teach physics: Problems and solutions," J. Grad. Teach. Assist. Dev. 7, 123 (2000).
${ }^{11}$ J. A. Gilreath and T. F. Slater, "Training graduate teaching assistants to be better undergraduate physics educators," Phys. Educ. 29, 200 (1994).

${ }^{12}$ F. Lawrenz, P. Heller, R. Keith, and K. Heller, "Training the teaching assistant," J. Coll. Sci. Teach. 22, 106 (1992).

${ }^{13}$ E. L. Jossem, "Resource letter EPGA-1: The education of physics graduate assistants," Am. J. Phys. 68, 502 (2000).

${ }^{14}$ K. M. Koenig and R. J. Endorf, "Study of TA's ability to implement the Tutorials in Introductory Physics and student conceptual understanding," in Proceedings of the 2004 Physics Education Research Conference, edited by J. Marx, P. Heron, and S. Franklin, AIP Conf. Proc. No. 720 (AIP, Melville, NY, 2004).

${ }^{15}$ T. O. Pride, S. Vokos, and L. C. McDermott, "The challenge of matching learning assessments to teaching goals: An example from the work-energy and impulse-momentum theorems," Am. J. Phys. 66, 147 (1998).

${ }^{16}$ L. C. McDermott and P. S. Shaffer, Instructor's Guide for Tutorials in Introductory Physics (Prentice-Hall, Upper Saddle River, NJ, 2002).

${ }^{17}$ A. Van Heuvelen, "Overview, Case Study Physics," Am. J. Phys. 59, 898 (1991).

${ }^{18}$ L. R. Jones, A. G. Miller, and J. F. Watts, "Conceptual teaching and quantitative problems solving; Friends or foes," J. Coop. Collab. Coll. Teach.1068-6118 10, 109 (2001). 